\title{
Hybridized Reinforcement of Natural Rubber/Styrene ButadieneRubber (NR/SBR) Blend with Treated Bis (3-Triethoxysilylpropyl) Tetrasulfide(Si 69)-Hybrid Carbon Black/Nanocalcium Carbonate Filler: Mooney Viscosity, Crosslink Density and Cure Characteristic
}

\author{
${ }^{1,2}$ Siti Nur Liyana Mamauod, ${ }^{3}$ Basirah Fauzi, ${ }^{2}$ Siti Noor Fazira Roslan and ${ }^{2}$ Roslinda Fauzi \\ ${ }^{1}$ Polymer Composites Research and Technology Center (PoCResT) Institute of Science, \\ ${ }^{2}$ Faculty of Applied Sciences, Universiti Teknologi MARA (UiTM), \\ 40450 Shah Alam, Selangor Darul Ehsan, Malaysia \\ ${ }^{3}$ Centre of Diploma Studies, Universiti Tun Hussein Onn Malaysia, \\ Bandar Universiti, 84600 Pagoh, Johor, Malaysia \\ nurliyana2219@salam.uitm.edu.my
}

\begin{abstract}
In this research, the Mooney viscosity, crosslink density and cure characteristics of the treated Silane-Carbon Black/Nanocalcium Carbonate (Si-CB/NCC) reinforced Natural Rubber/Styrene Butadiene Rubber (NR/SBR) composites were investigated. The results showed that the addition of treated CB/PCC at different concentration of silane coupling agent increases the crosslink density where the superior crosslink density of composites was achieved at $4 \mathrm{wt} . \%$ of silane treatment (NR-SBR/CB-NCC4-Si69). At this composition an increment of crosslink density is about $11 \%$ as compared to the untreated filler-BR/SBR composites. A positive correlation between crosslink density and Mooney viscosity behaviours has been shown that by increasing the 3D-network structure, it increases the viscosity and compactness of the rubber composites structures. The formation of optimum active sites on the $\mathrm{CB}$ and PCC filler surfaces led to accelerate the vulcanisation process about $17 \%$ as compared to untreated filler-NR/SBR composites where these active sites of fillers surface led to an increase of the adhesion at the interface between treated fillers and NR/SBR matrix. It is noted that sufficient amount of silane is required to improve the overall properties because excessive silane content gave the plasticising effect to the composites structure, thus, resulting in the reduction of other properties.
\end{abstract}

Key words: Treated silane-carbon black/nanocalcium carbonate, NR/SBR matrix, silane coupling agent, crosslink density, Mooney viscosity, cure characteristics

\section{INTRODUCTION}

Polymer blends is one of the significant areas of research activity in recent years. New formulations based on blends have been widely formulated to meet the several industrial requirements such as the need of easier processing and broadening of the properties range, either by varying the type or by relative amounts or morphology of each component (Khalf et al., 2010; Sionkowska, 2011; Cao et al., 2019). In addition, blends of polymer is an efficient way to improve the mechanical properties compared to those with the single components (Sionkowska, 2011). Several research has been conducted by blending two or more rubbers in order to achieve specific properties based on the application required (Manshaie et al., 2011; Mamauod et al., 2018; Pongtanayut et al., 2013; Noriman et al., 2010) for instance, blending of Natural Rubber (NR) and Styrene Butadiene Rubber (SBR). Polymers can be blended directly by simply mixing the rubber under specific conditions or by using an appropriate coupling agent. NR/SBR blends was carried out for many reasons such as to lower the compound costs, to ease fabrication and to improve the performance of the properties of the rubber blends.

Blends of polymer alone without filler have limit its applications due to its poor performance for critical applications. Hybrid filler is well-known in the rubber industry now a days. An ideal hybrid filler can give best feature rather than the single filler used (Tangudom et al., 2014; Ooi et al., 2013; Roy et al., 2016). The optimum formulation of hybrid filler achieved the enhancement of strength and strength-related properties, abrasion resistance, hardness and modulus. Hence, hybrid fillers

Corresponding Author: Siti Nur Liyana Mamauod, Polymer Composites Research and Technology Center (PoCResT), Institute of Science, Universiti Teknologi MARA (UiTM), 40450 Shah Alam, Selangor Darul Ehsan, Malaysia nurliyana2219@salam.uitm.edu.my 
are used in this project to improve the strength properties of the NR/SBR blends. Hybrid filler used was Carbon Black (CB) and Nano-Calcium Carbonate (NCC). The spherical in shape of NCC was chosen due to its large surface area which can interact well with the polymer matrix. Nano-Calcium Carbonate (NCC) provides a good dispersion in morphological properties even a little amount of NCC is added to the blends. Compared to the conventional composites, polymer nano-composites have drawn important interest from industry due to the improvements in material properties at very fine level with very low nano-filler loading. The outstanding of mechanical, electrical and thermal properties of Carbon Black (CB) making it as an ideal filler to be used in polymer composites. In general, $\mathrm{CB}$ is low polarity filler compared to NCC filler which influences and limits its interaction with polar and non-polar surfaces. Additionally, it causes optimisation in terms of dispersion which was difficult to achieve. Therefore, surface treatment was carried out first, on the filler surfaces in order to improve the interaction between polar and non-polar phases of fillers and NR/SBR matrix. The utilization of hybrid filler or blend NCC and CB in rubber should give the benefits from each filler, since, they have their own advantages.

In this research, the hybrid filler was treated by silane coupling agent (bis (3- triethoxysilylpropyl) tetrasulphide (Si69) before incorporated into the NR/SBR blends. The effect of treated hybrid $\mathrm{CB} / \mathrm{NCC}$ filler towards the crosslink concertation, Mooney viscosity and crosslink density was studied.

\section{MATERIALS AND METHODS}

The raw rubbers used were Natural Rubber (NR) with grade SMR 10 and Styrene-Butadiene Rubber (SBR) with grade SBR 1502 and Epoxidized Natural Rubber (ENR) provided by Lembaga Getah Malaysia (LGM). Besides, the commercial fillers used in this study are hybrid fillers of Nano-size Calcium Carbonate (NCC) and carbon black (N330). The other compounding ingredients used to develop rubber compounds were Zinc Oxide ( $\mathrm{ZnO}$ ), Stearic Acid (HST), sulphur (curatives), accelerator (CBS) and silane coupling agent (Silane 69) which purchased from the local suppliers with analytical grades.

Surface treatment of CB and NCC by silane bis (3-Triethoxysilylpropyl) tetrasulfide solutions: The silane coupling agent used was Si-69. The silane content varied from $0-10 \%$ by weight (wt.\%) of the Carbon Black (CB) and Nano-Calcium Carbonate (NCC) hybrid filler. The silane solution was prepared by mixing with ethanol. For silane solution with content of 2 wt. \% of Si- 69 was mixed with $500 \mathrm{~mL}$ of ethanol and then stirred for $30 \mathrm{~min}$. Next, 4 pphr of NCC is then added into the silane

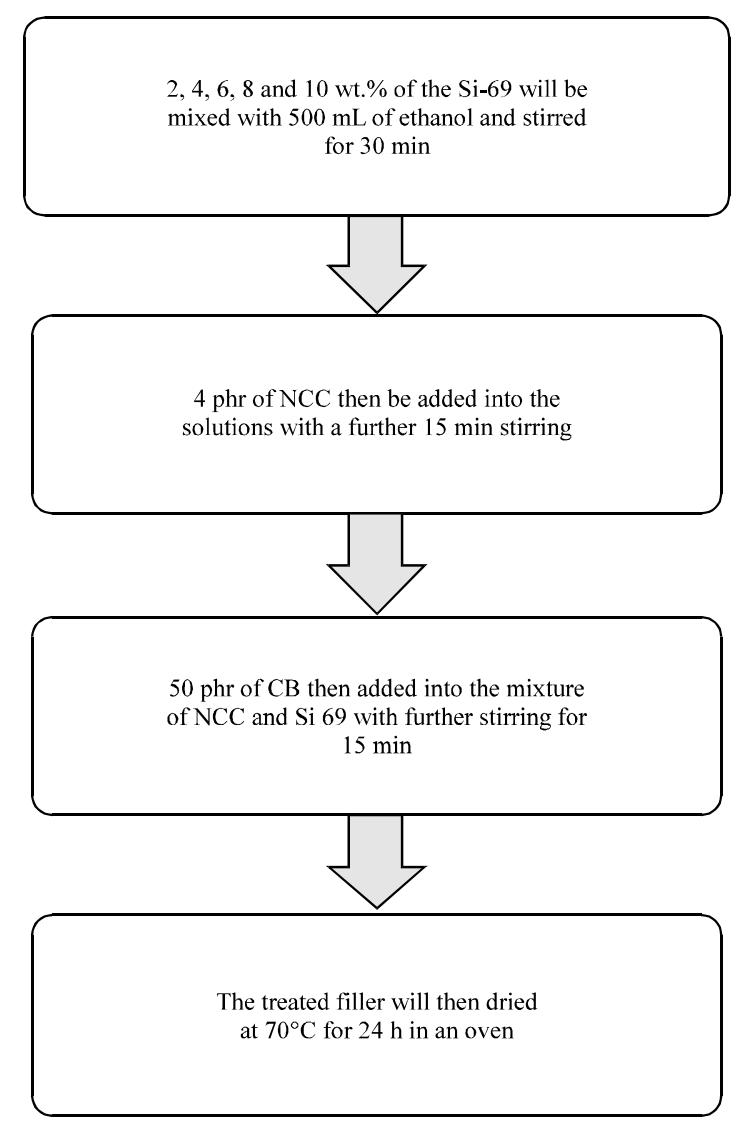

Fig. 1: Flowchart of surface treatment of $\mathrm{CB} / \mathrm{NCC}$ by Si- 69

solution with a further $7 \mathrm{~min}$ stirring. The $50 \mathrm{phr}$ of CB was then added into the mixture of NCC and Si- 69 with further stirring for $7 \mathrm{~min}$ in order to ensure a uniform distribution of the coupling agent on the fillers surface. The treated fillers were then dried at $70^{\circ} \mathrm{C}$ for $12 \mathrm{~h}$ in an oven until a constant weight was achieved. Similarly, 4, 6, 8 and 10 wt.\% of silane coupling agents on both $\mathrm{CB}$ and $\mathrm{NCC}$ fillers surface were prepared by varying the initial Si- 69 contents for the same amount of $\mathrm{CB}$ and NCC filler using the same procedure. Figure 1 shows the steps of preparing the treated $\mathrm{CB} / \mathrm{PCC}$ filler.

\section{Preparation of treated CB/PCC-NR/SBR composites:} The formulation of the rubber compounds is as follows: $60 \mathrm{phr}$ of Natural Rubber (NR), $40 \mathrm{phr}$ of Styrene-Butadiene Rubber (SBR), 2 phr of Epoxidized Natural Rubber (ENR), $5.0 \mathrm{phr}$ Zinc Oxide ( $\mathrm{ZnO}), 2.0$ phr stearic acid, $1.2 \mathrm{phr} \mathrm{N}$-Cyclohexyl-2-benzothiazole Sulfonamide (CBS) and $1.8 \mathrm{phr}$ sulphur (Table 1). In the mastication step, the NR, SBR and ENR was masticated on a laboratory two-roll mill for $5 \mathrm{~min}$ and was then mixed with a zinc oxide and stearic acid for another $5 \mathrm{~min}$. Zinc oxide and stearic acid are important ingredients in rubber compounding in which zinc oxide acts as activator and 


\begin{tabular}{lllllll}
\multicolumn{7}{l}{ Table 1: Formulation of treated NR/SBR composites } \\
Ingredients & F1 & F2 & F3 & F4 & F5 & F6 \\
\hline NR & 60 & 60 & 60 & 60 & 60 & 60 \\
ENR & 2 & 2 & 2 & 2 & 2 & 2 \\
SBR & 40 & 40 & 40 & 40 & 40 & 40 \\
NCC & 4 & 4 & 4 & 4 & 4 & 4 \\
Silane & 0 & 2 & 4 & 6 & 8 & 10 \\
N330 & 50 & 50 & 50 & 50 & 50 & 50 \\
CBS & 1.2 & 1.2 & 1.2 & 1.2 & 1.2 & 1.2 \\
ZnO & 5 & 5 & 5 & 5 & 5 & 5 \\
HST & 2 & 2 & 2 & 2 & 2 & 2 \\
Sulphur & 1.8 & 1.8 & 1.8 & 1.8 & 1.8 & 1.8 \\
\hline
\end{tabular}

stearic acid acts as co-activator. Both of them need to be added together to increase speed of vulcanisation. Hence, zinc oxide acts as universal activator used in almost all rubber compounds. It does not dissolve in rubber and cannot be used alone as an activator. However, with the combination of stearic acid the oxide particles of HST are covered with zinc stearate that dissolves in rubber making, it is possible to be used as an activator. After that, a specified content of treated hybrid filler is added for another $10 \mathrm{~min}$. Next, CBS was added and followed by the addition of sulphur into the compounding to ensure that the vulcanization process occurs. After it ended, the compounding will be sheeted out and kept overnight before further use. This compounding process took about $25 \mathrm{~min}$

Determination of cure characteristics: Cure characteristics of rubber composites were determined by using an Oscillating Disc Rheometer (ODR). The temperature of upper and lower dies was set to $180^{\circ} \mathrm{C}$ and 100 bar into $2 \mathrm{~mm}$ thick sheet. The data of cure characteristics such as scorch time (ts2), optimum cure time ( $\mathrm{t} 90)$, Minimum torque $(\mathrm{ML})$, Maximum torque $(\mathrm{MH})$ and delta torque were obtained from cure curve.

Determination of Mooney viscosity: Mooney viscosity $\left(\mathrm{ML}(1+4), 100^{\circ} \mathrm{C}\right)$ was tested using a Mooney viscometer. The testing was conducted in accordance to ASTM D 1646. Some data obtained from the testing are Mooney peak, Mooney viscosity and stress relaxation.

Determination of crosslink density: Degree of swelling was measured using Flory-Rehner Eq. 1 where the cured rubber composite samples were cut into $2 \times 2 \times 0.2 \mathrm{~cm}$ and immersed into toluene for a few days until saturation level was achieved. The amount of solvent penetrates in the cured samples was recorded and be used to calculate the crosslink density:

$$
-\operatorname{In}\left(1-V_{\mathrm{r}}\right)-\mathrm{V}_{\mathrm{r}}-\psi \mathrm{V}_{\mathrm{r}}^{2}=2 \rho \mathrm{V}_{\mathrm{o}}[\mathrm{X}]_{\mathrm{phy}} \mathrm{V}_{\mathrm{r}}^{1 / 3}
$$

Where:

$\mathrm{V}_{\mathrm{r}}=$ The Volume fraction of rubber

$\Psi=$ The rubber-solvent interaction parameter

$\rho=$ The density of the polymer

$\mathrm{V}_{0}=$ The molar Volume of solvent

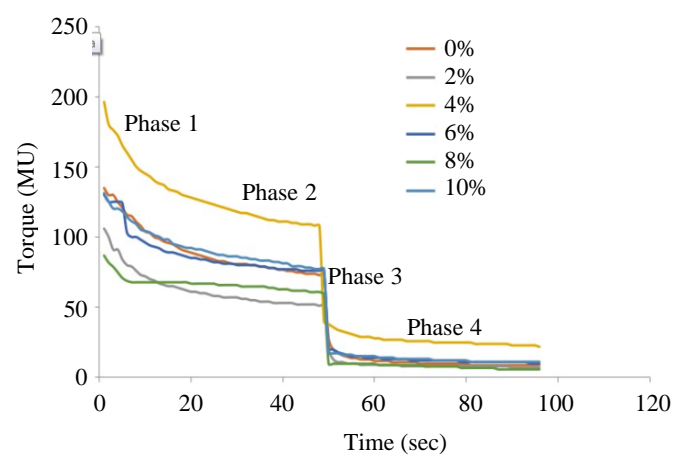

Fig. 2: Mooney viscosity of NR/SBR composites treated by both $\mathrm{CB} / \mathrm{NCC}$ fillers at different silane loading

\section{RESULTS AND DISCUSSION}

Mooney viscosity: Mooney Viscosity (MV) test was conducted to measure the viscosity of raw rubbers. Its properties are dependent on the molecular weight, molecular weight distribution interaction between filler-matrix phase, molecular structure such as stereochemistry and polymer branching and non-rubber constituents (Sapkota et al., 2013). The result of MV of Si-CB/NCC-NR/SBR composites was shown in Fig. 2. As it can be seen that there are 4 phases of MV curves of composites. At phase 1, it was indicated that the Mooney peak reflects on the green strength of rubber composites. Mooney peak showed the highest value of viscosity compared to other phases. NR-SBR/CB-NCC4-Si69 composites showed the highest value of $\mathrm{MV}$ and it is contributed to the strong interaction between treated $\mathrm{CB} / \mathrm{PCC}$ filler surface at 4 wt. $\%$ of silane and NR/SBR matrix. The sufficient surface activity of fillers would enhance and strengthen the filler-matrix adhesion. Hence, in increasing the resistivity of rubber chains to deform and fracture upon shearing effect of rotor and rubber composite phases (Tavakoli et al., 2012). High amount of silane coupling agent led to decrease the viscosity due to the plasticizing effect. However, the MV decreases slowly with increasing the heating period where the rubber composites samples started to soften due to the transition of strong to weak intermolecular force between polymer structures, thus, resulting in lowering the entropy of polymer chains. The sufficient heating period would generate energy to overcome interfacial interaction between treated CB/NCC filler and NR/SBR phases. By lowering these interactions would enhance the flexibility and mobility of polymer chains. At phase 3 , it showed drastic decrease in torque when the rotor was stopped and no more shearing occurred. In phase 4, the polymer chains in rubber blends start to relax and cause the entropy of the sample to slowly increase due to the entanglement of short polymer chains. 
Table 2: Cure characteristics of NR/SBR composites treated by both CB/NCC fillers at different Si-69 loading

\begin{tabular}{|c|c|c|c|c|}
\hline Designation & $\begin{array}{l}\text { Minimum } \\
\text { torque } \\
\text { (ML) }\end{array}$ & $\begin{array}{l}\text { Maximum } \\
\text { torque } \\
(\mathrm{MH})\end{array}$ & $\begin{array}{c}\text { Delta } \\
\text { torque } \\
\text { (MH-ML) }\end{array}$ & $\begin{array}{c}\text { Optimum } \\
\text { cure time } \\
\text { (t90) }\end{array}$ \\
\hline NR-S & 120 & 0 & 13 & 1.50 \\
\hline NR-SBR/C & 18. & 49.5 & 30 & 90 \\
\hline NR-SBR/CB-NCC4-Si69 & 20.5 & 62.7 & 42.2 & 1.25 \\
\hline NR-SBR/CB-NCC6-Si69 & 19.0 & 59.0 & 40. & 1.38 \\
\hline NR-SBR/CB-NCC 8- Si69 & 26.5 & 64.0 & 37.5 & 1.33 \\
\hline NR-SBR/CB-NCC10-Si69 & 19.0 & 52.2 & 33.2 & 1.30 \\
\hline
\end{tabular}

Cure characteristics: Cure characteristics of treated Si-CB/NCC-NR/SBR composites were summarised in Table 2. It can be seen that the delta torque of NR/SBR-CB/NCC blends by treating both CB/NCC fillers at different silane loading increase as the silane content increase. Delta torque is the difference between the maximum and minimum torques which indicates the filler matrix interaction of treated $\mathrm{CB} / \mathrm{NCC}$ fillers and NR/SBR matrix. The greater the value of torque difference, the higher is the crosslink concentration. Delta torque of rubber blends drastically increases ranging from $0-4 \%$ of silane loading. It can be observed that the delta torque of NR-SBR/CB-NCC4-Si69 is the highest linkage between CB/NCC fillers and NR/SBR phases. A sufficient of surface activation of treated $\mathrm{CB}$ and $\mathrm{NCC}$ filler influenced the interaction with rubber phases and form a rigid composites material and hence increase the $\mathrm{MH}$ and $\mathrm{ML}$. Meanwhile, the optimum cure time of rubber blends decreases as the silane concentration decreases. The reduction of optimum cure time attributed to the good interaction and interfacial adhesion between the rubber and fillers.

Crosslink concentration: The effect of different silane content on $\mathrm{CB} / \mathrm{NCC}$ filler surface reinforced NR/SBR composites towards the crosslink conctration was presented in Fig. 3. It can be seen that the NR/SBR matrix reinforced with 4 wt.\% of silane treated $\mathrm{CB} / \mathrm{NCC}$ filler possesses the highest crosslink density among other formulations. The existence of sufficient surface activity on both surfaces of CB and NCC filler in the rubber blends provides stable microstructures for the fillers to be well dispersed in the rubber blends leading to the enhancement of interfacial contact between rubber and filler phases. Increase in crosslink density might be due to the C-S linkages formed by the chemical reaction between the rubber and silane-fillers surface which silane could act as a crosslinker in the vulcanizates (Fang et al., 2014). However, the crosslink density of the rubber blends starts to decrease up to $4 \%$ of silane loading. This might be due to the self-condensation reaction of Si-69 resulting in the formation of polysiloxane molecules on the filler surface and acts as a plasticizer between rubber and filler phases.

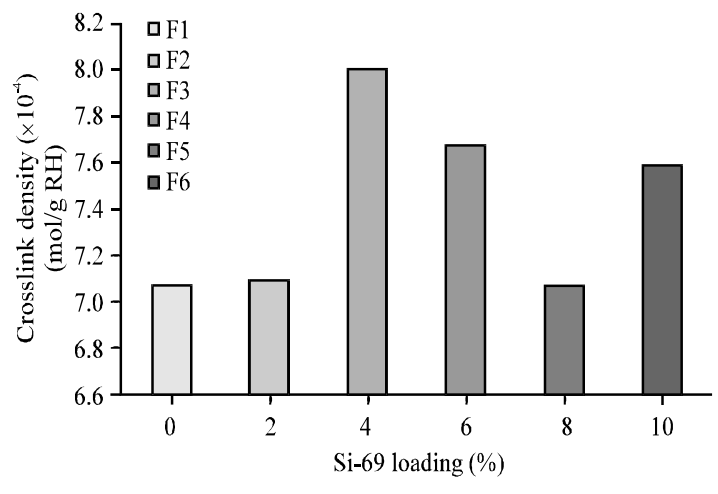

Fig. 3: Crosslink density of NR/SBR composites treated by both $\mathrm{CB} / \mathrm{NCC}$ fillers at different silane loading

Thus, this reduced the crosslinking sites between rubber and filler in the rubber blends. This condition is also known as plasticization effect (Kapgate et al., 2014). The drastic drop of the crosslink density in the rubber blends at $8 \%$ of Si-69 loading might be due to the poor filler matrix interfacial adhesion. Thus, this reduced the crosslinking sites between rubber and filler phases in the rubber blends. It can be concluded that an optimum content of Si-69 required to enhance the interaction between rubber and filler phases is $4 \mathrm{wt} . \%$.

\section{CONCLUSION}

From the observation and results obtained, the following conclusion can be drawn as below: by conducting the surface treatment using silane coupling agent on the $\mathrm{CB}$ and NCC fillers surface enhanced the surface activity of fillers and improved the interaction between polar-filler and non polar-rubber matrix and also strengthen the reinforcing effect towards the rubber blends properties. The optimisation of silane content required to treat hybrid $\mathrm{CB} / \mathrm{NCC}$ filler surface was identified at $4 \mathrm{wt} \%$ of silane where it can be contributed the maximum crosslink interaction between filler and matrix phases, thus, resulting in increasing the viscosity value. The formation of excessive of active sites on the filler surface by silanization process would cause the plasticizing effect.

The optimum cure time of treated filler-NR/SBR composites does not significantly effect to the silane content use to treat filler surface. As a whole, this project has contributed to knowledge of understanding on the rubber matrix reinforced by hybrid treat filler through an industrial feasible processing technique that enhanced the Mooney viscosity, crosslink density and cure characteristics. 


\section{ACKNOWLEDGEMENT}

The researchers gratefully acknowledge the research facilities and financial support from the Polymer Composites Research and Technology Center (PoCRes T) Institute of Science (IOS) and Research Management Institute (RMI), Universiti Teknologi MARA (UiTM), Malaysia.

\section{REFERENCES}

Cao, X., W. Dong, M. He, J. Zhang and F. Ren et al., 2019. Effects of blending sequences and molecular structures of the compatibilizers on the morphology and properties of PLLA/ABS blends. RSC. Adv., 9: 2189-2198.

Fang, Q., B. Song, T.T. Tee, L.T. Sin and D. Hui et al., 2014. Investigation of dynamic characteristics of nano-size calcium carbonate added in natural rubber vulcanizate. Compos. Part B. Eng., 60: 561-567.

Kapgate, B.P., C. Das, D. Basu, A. Das and G. Heinrich et al., 2014. Effect of silane integrated sol-gel derived in situ silica on the properties of nitrile rubber. J. Appl. Polym. Sci., Vol. 131, 10.1002/app.40531

Khalf, A.I., D.E. Nashar and N.A. Maziad, 2010. Effect of grafting cellulose acetate and methylmethacrylate as compatibilizer onto NBR/SBR blends. Mater. Des., 31: 2592-2598.

Mamauod, S.N.L., B. Fauzi, N.A. Suhaimi, R. Fauzi and A.Z. Romli, 2018. Preparation and charaterization of treated BIS [3-(triethoxysi-lyl) propyl] tetrasulfide (Si-69)-hybrid CB/PCC fillers reinforced NR/SBR composites: Cure characteristic, mooney viscosity and cross-link density. Adv. Compos. Lett., 27: 261-365.

Manshaie, R., S.N. Khorasani, S.J. Veshare and M.R. Abadchi, 2011. Effect of electron beam irradiation on the properties of natural rubber (NR)/Styrene-Butadiene Rubber (SBR) blend. Radiat. Phys. Chem., 80: 100-106.
Noriman, N.Z., H. Ismail and A.A. Rashid, 2010. Characterization of styrene butadiene rubber/ recycled acrylonitrile-butadiene rubber (SBR/NBRr) blends: The effects of epoxidized natural rubber (ENR-50) as a compatibilizer. Polym. Test., 29: 200-208.

Ooi, Z.X., H. Ismail and A.A. Bakar, 2013. Optimisation of oil palm ash as reinforcement in natural rubber vulcanisation: A comparison between silica and carbon black fillers. Polym. Test., 32: 625-630.

Pongtanayut, K., C. Thongpin and O. Santawitee, 2013. The effect of rubber on morphology, thermal properties and mechanical properties of PLA/NR and PLA/ENR blends. Energy Procedia, 34: 888-897.

Roy, K., M.N. Alam, S.K. Mandal and S.C. Debnath, 2016. Silica-coated nano calcium carbonate reinforced polychloroprene rubber nanocomposites: Influence of silica coating on cure, mechanical and thermal properties. J. Nanostruct. Chem., 6: $15-24$.

Sapkota, J., M. Poikelispaa, A. Das, W. Dierkes and J. Vuorinen, 2013. Influence of nanoclay-carbon black hybrid fillers on cure and properties of natural rubber compounds. Polym. Eng. Sci., 53: $615-622$.

Sionkowska, A., 2011. Current research on the blends of natural and synthetic polymers as new biomaterials: Review. Prog. Polym. Sci., 36: 1254-1276.

Tangudom, P., S. Thongsang and N. Sombatsompop, 2014. Cure and mechanical properties and abrasive wear behavior of natural rubber, styrene-butadiene rubber and their blends reinforced with silica hybrid fillers. Mater. Des., 53: 856-864.

Tavakoli, M., A.A. Katbab and H. Nazockdast, 2012. NR/SBR/organoclay nanocomposites: Effects of molecular interactions upon the clay microstructure and mechano-dynamic properties. J. Appl. Polym. Sci., 123: 1853-1864. 